\title{
T-Cell Receptor Gene
}

National Cancer Institute

\section{Source}

National Cancer Institute. T-Cell Receptor Gene. NCI Thesaurus. Code C18017.

The T-cell antigen receptors consist of a heterodimer of integral membrane glycoproteins. Two distinct receptors exist, alpha/beta and gamma/delta. Alpha/beta receptors are found on helper and cytotoxic T-cells and are specific for antigenic peptides presented in association with MHC gene products. Gamma/delta receptors, found in association with CD3, directly recognize proteins and non-proteinacious phospho-ligands. Alpha/beta and gamma/delta are non-covalently associated with CD3gamma, -delta, -epsilon, and -zeta proteins, forming the TCR-CD3 complex, which activate MAPKs and JNK1 through the CD3 antigens, the adaptor protein LAT, and tyrosine kinases LCK and ZAP70. The genes for T-cell receptor subunits are encoded by distinct gene elements that are assembled by somatic rearrangement during $\mathrm{T}$-cell development. Translocations and inversions of these loci are observed in human T-cell leukemias and lymphomas. 